\title{
The terrestrial carbon/nitrogen ratio: Insight from the composition of natural gases
}

\author{
BERNARD MARTY
}

${ }^{1} \mathrm{CRPG} / \mathrm{CNRS} \&$ Université de Lorraine

15 Rue Notre Dame des Pauvres, 54501 Vandoeuvre les Nancy France bernard.marty@univ-lorraine.fr

The terrestrial $\mathrm{C} / \mathrm{N}$ ratio is a key parameter which permits to set constraints on the volatile inventory of our planet, on the conditions of Earth's formation, as well as on planetary processing in the inner solar system [1-3]. The bulk silicate Earth (BSE) value appears higher than solar or chondritic ratios but the cause of this difference is discussed between planetary processing, fractionation during metal/silicate partitioning, and/or during atmospheric escape. The $\mathrm{C} / \mathrm{N}$ ratio of the surface reservoirs (atmosphere, crust, sediments) is reasonably well known, but that of the mantle is subject to controversy, between a value around 80 [1] and ratios $>300$ [2]. Both estimates are anchored to the nitrogen content of the BSE from K-N-Ar correlations of mantle-derived samples [4]. The lower value is derived from a BSE carbon budget scaled to non-volatile trace elements [3], and the higher one is from $\mathrm{C} / \mathrm{N}$ measurements of variably degassed MORB and OIB glasses, corrected for degassing fractionation using noble gas (i.e., radiogenic ${ }^{4} \mathrm{He} /{ }^{40} \mathrm{Ar}$ ) systematics. Here I use chemical and isotopic data from $\mathrm{CO}_{2}$-rich volcanic, geothermal and hydrothermal gases sampled in continental, oceanic, and mantle plume settings. All data considered here have (i) ${ }^{40} \mathrm{Ar} /{ }^{36} \mathrm{Ar}$ ratios higher than the atmospheric value, (ii) signatures of mantle $\mathrm{He}, \mathrm{Ne}$ and $\mathrm{Xe}$, and (iii) ${ }^{4} \mathrm{He} /{ }^{40} \mathrm{Ar}$ ratios close to the mantle production/accumulation ratio. $\mathrm{CO}_{2}$-rich gases show mantle $\mathrm{C} / \mathrm{N}$ ratios higher than 200 , with high $\mathrm{C} / \mathrm{N}$ ratios up to 1,300 recorded in mantle plume-related gases. These data are consistent with those obtained for oceanic basalt glasses [2], and support a non-chondritic C/N ratio for the BSE. In the light of these new estimates, I shall revise the carbon content of the BSE and argue that high pressure metal-silicate partitioning is responsible for the BSE $\mathrm{C} / \mathrm{N}$ fractionation.

[1] E. Bergin et al. PNAS 112, 29 8965-8970 (2015). [2] B. Marty, EPSL 313-314, 56-66 (2012). [3] M. Hirschmann Amer. Mineral. 101, 540-553 (2016). [4] B. Marty \& N. Dauphas EPSL 206, 397-410 (2003). 